Comparing the effect of teaching collocations versus single words on speaking fluency and accuracy

Memarian-Mojarab, Mina

Semnan University, Iran (memarian87@semnan.ac.ir)

Farjami, Hadi $\bowtie$

Semnan University, Iran (hfarjami@semnan.ac.ir)

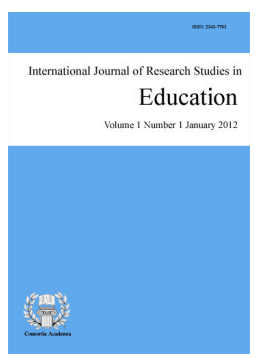

ISSN: 2243-7703 Online ISSN: 2243-7711

OPEN ACCESS

\title{
Abstract
}

This study attempted to investigate the effect of collocation-based teaching of vocabulary on speaking fluency and accuracy and compare it with teaching single words. To this end, after administrating the speaking section of Preliminary English Test (PET), 30 pre-intermediate L2 learners were selected out of 50 and assigned to experimental and control groups. The participants in the experimental group received collocation-based vocabulary instruction, whereas the participants in control group received single-word teaching of vocabulary. PET interviews provided evidence for participants' speaking fluency and accuracy before the treatment, while PET interviews and an achievement test measured their post-treatment speaking accuracy and fluency. The result of independent-samples t-tests showed that the participants in the experimental group outperformed participants in the control group with respect to speaking fluency and accuracy, indicating that collocation-based teaching of vocabulary is more effective in enhancing speaking fluency and accuracy than teaching single words.

Keywords: collocations; single-words; speaking accuracy; speaking fluency; vocabulary teaching 


\section{Comparing the effect of teaching collocations versus single words on speaking fluency and accuracy}

\section{Introduction}

One aspect of Second Language Acquisition (SLA) that has attracted a lot of attention is vocabulary learning. When it comes to learning vocabulary in depth, it is impossible to avoid collocations and other types of formulaic language. Competence in using collocations is one of the ways in which native and non-native speakers become linguistically different (Ellis, 2001, 2006; Koya, 2006; McCarthy, 2004; Nation, 2008, 2014; Wouden, 1997). If someone says I did a few mistakes they will be understood, but a fluent speaker of English will say I made a few mistakes. Why do we say fast food instead of quick food? The reason is collocations. Teaching collocations seems apposite to learners' communicative realities and enables them to speak naturally. This stands to reason because as strong research evidence shows (see for example, Schmitt, 2010) the lexical system behaves not as isolated words which are linearly and mechanically strung together, but rather as a network of strongly associated words which tend to occur together. The present study was an attempt to empirically investigate the effect of collocation-based teaching of vocabulary on speaking fluency and accuracy and compare it with the effect of teaching single words. It seemed a worthwhile attempt because, as stated above, normal language includes a large amount of formulaic language, including collocations, which are instrumental in successful communication. Although the effect of helping learners gain mastery over collocations is generally acknowledged now, providing empirical support for the effectiveness and consequences of such a teaching strategy can further guide and boost the practice of people involved in the field of foreign language teaching (See Wray, 2002) for a comprehensive bibliography of research on formulaic language and collocations). More specifically, investigating whether the positive consequences of mastering colocations realize through affecting accuracy, fluency, or both of these two principal aspects of communication can provide much insight for the practitioners involved in language teaching.

\section{Review of literature}

The pieces of language which Halliday (1966) called "collocations" have also been called formulae, multi-word units, collocations, prefabricated routines, conventionalized forms, holophrases, ready-made utterances, lexical chunks, fixed phrases, prefabricated phrases, etc. (Schmitt, 2010; Wray, 2002). In fact, Wray (2002) identified more than 50 labels to refer to the conventionalized and formulaic sequences of words. Some researchers in cognitive linguistics and psychology (e.g., Croft \& Cruise, 2004; Ellis, 2001; Goldberg, 2006) suggest that the basic units of language learning and processing are these conventionalized constructions. Sinclair (1991, the once director of the Cobuild project, the largest lexicographic work in the English language to date, captures this important claim in his Idiom Principle:

A language user has available to him or her a large number of semi-pre-constructed phrases that constitute single choices, even though they might appear to be analyzable into segments. (p. 110)

He suggests that the idiom principle is easily applicable to most normal texts.

Not surprisingly, native language speaker have a large stock of collocations available to them. So, native-like competence and fluency on the part of second language learners demand much idiomaticity (Ellis, 2001).In fact, this rich stock of collocations and their varied patterns explain why language learning takes so long, why it requires exposure to authentic sources, and why there is currently so much interest in corpus linguistics (Biber, Conrad \& Reppen, 1998; Hunston \& Francis, 1996; McEnery \& Wilson, 1996).

Michael Lewis' lexical approach emphasizes the development of learners' lexical proficiency, which include 
both words and word combinations (Lewis, 1993). In this approach, particular attention is given to word combinations whose uses have been conventionalized, i.e., collocations and fixed expressions. As Lewis maintains, lexis-based teaching should not be interpreted as teaching isolated words; teacher should help learners view language in perspective using collocations instead of trying to split things into smaller pieces (Lewis, 1997).

Several studies have focused on teaching and learning collocations. Zhang (1993) conducted comparative research on the use of collocations by native and non-native English speakers' in their writings. Results established that English learners with lower levels of proficiency used more grammatical collocations and fewer lexical collocations. Arnaud and Savignon (1997) employed a multiple-choice test to explore the acquisition of low-frequency words and multi-word lexical chunks by advanced second language learners. Their findings revealed that students were more successful in producing low-frequency words than producing complex lexical units. Arnaud and Savignon (1997) claimed that this may be due to the complexity of lexical units, to which some learners did not pay the necessary attention to learn. They also attributed this finding to a lack of awareness on the part of learners about the significance of collocations.

Nesselhauf (2003) investigated the use of verb+noun collocations, e.g., take a break and shake one's head, in essays by German-speaking learners of English. Nesselhauf (2003) used the framework originally designed by Howarth (1998) and defined three categories of verb+noun collocations: 1) free combinations, where verbs and nouns are used without any restriction, e.g., want a car; 2) limited-restriction collocations such as take a picture, where the noun is unrestricted but verb is restricted (one can alternatively say take a photograph); and 3) idioms, e.g., sweeten the pill, where verbs and nouns are restricted and substitution is not the norm. As the result of this study showed, the greatest proportion of the errors was made with limited-restriction collocations (79\%), followed by free combinations (23\%) and idioms (23\%).

Webb, Newton, and Chang (2013) researched the effect of repetition on the learning of collocations. In their study, Taiwanese university students learning English as a foreign language simultaneously read and listened to one of the four versions of modified graded readers in which 18 collocations were repeated different number of times: 1, 5, 10, or 15 times. Measurement of the participants' receptive and productive mastery of the forms and meanings of these 18 collocations revealed that (a) collocations can be learned incidentally through reading and listening to graded readers and (b) there is a positive correlation between the number of encounters and learning collocations. In this study, learners who encountered the target collocations 15 times while reading and listening to a graded reader, had the greatest gains.

Finally, Boers, Eyckmans, Kappel, Stengers, and Demecheleer (2006) conducted an experiment to assess the extent to which teaching formulaic expressions can help learners present themselves as proficient L2 users and how emphasizing on 'noticing' of such expressions in instruction can help language learners add such items to their vocabulary store. In this study, over the course of 22 teaching hours, 32 college students of English were exposed to considerable authentic listening and reading materials. The experimental students, who were made aware of conventional word combinations, were perceived to be more proficient than the control group by two interviewers. Two other judges counted the number of word combinations in the interviews which were considered to be conventional formulas. There was a positive correlation between their counts and the oral test results, which means that raising learners' awareness of collocations and helping them expand their stock of formulaic sequences can be an effective strategy for improving oral proficiency.

Two major aspects of language proficiency and production are fluency and accuracy (Jong, Steinel, Florijn, Schoonen, \& Hilstijn, 2012). Proficient language users are expected to produce it easily and smoothly and be able to talk with native-speakers and others freely and comfortably. Being a fluent language user means being able to use available linguistic resources to maintain the flow of communication without experiencing breakdowns in communication (Alderson, 2005). Accuracy, on the other hand, refers to the correct use of the language components, including vocabulary, grammar, and pronunciation (Harmer, 2001). For example, are the 
words used and the way they are combined correct? Are the prepositions used the right ones? Although fluency has been emphasized in the communicative approach to language teaching and is sometimes explained in contrast with accuracy (Révész, Ekiert, \& Torgersen, 2016), the emphasis should not be taken as the irrelevance or triviality of accuracy. In fact, research has found that these two elements in communication are associated with each other and support communication in tandem (Skehan, 2009).

A common problem encountered by English language learners is that they cannot express themselves as naturally as native English speakers do. Frequently, the wrong choice of vocabulary items makes their language sound unnatural and, in some cases, ungrammatical. Many times, they create long, awkward, pidgin-like constructions because they do not know the collocations which precisely express what they intend to say. This stems from the fact that they are not familiar with collocations and have not learned and used them. What makes the issue even more serious is that comparisons of written and spoken corpora have demonstrated that collocations are even more frequent in spoken language (Biber, Johansson, Leech, Conrad, \& Finegan, 2002; Brazil, 1995; Leech, 2000). In view of the significance of language chunks and collocations in language use and the needs of language learners, this study investigated the effect of collocation-based teaching of vocabulary on learners' speaking fluency and accuracy and compared it with single-word teaching of vocabulary.

The following questions guided the study:

$>$ Does collocation-based teaching of vocabulary to Iranian EFL learners improve their speaking fluency more than single word-based teaching of vocabulary?

$>$ Does collocation-based teaching of vocabulary to Iranian EFL learners improve their speaking accuracy more than single word-based teaching of vocabulary?

\section{Methodology}

\subsection{Participants}

The participants in this study were 30 female students at the pre-intermediate level of English proficiency, studying English as a foreign language in Ariyana English Institute in Pakdasht, Tehran, Iran. These students had been studying English at least for two years in a language institute. Their age ranged from 15-22 years.

\subsection{Materials}

The materials used in this investigation are briefly introduced below.

Intermediate Vocabulary Book - authored by B J Thomas (1986) and is designed for students who already have a reasonable command of the basic structures of English and wish to expand their vocabulary. This book was used as a source of target vocabulary for participants in this study since it was close to language proficiency level of participants and categorized the items on a thematic basis. Three topics were selected considering the age range and interest of the participants. Ten new words were selected from each section.

Longman Active Study Dictionary - includes 100,000 words, phrases and meanings, 6000 synonyms, antonyms and related words as well as 20,000 collocations and typical word combinations (Longman Active Study Dictionary, 2010). This dictionary has been prepared for English learners of intermediate level of proficiency and provides learners with highly frequent collocations; therefore, it was used with the experimental group of this study.

Preliminary English Test (PET) - also known as Preliminary, is a low-intermediate English language examination provided by Cambridge English Language Assessment (previously known as University of Cambridge ESOL examinations) and demonstrates the ability to communicate in using English for everyday 
purposes. It includes these sections: Reading and Writing (90 minutes), Listening (30 minutes), Speaking (a 10-minute interview). Candidate speaking performance is assessed based on the Common European Framework of Reference. The assessor gives 0-5 marks for each of the following criteria: Grammar and Vocabulary; Discourse Management; Pronunciation; and Interactive Communication. The interlocutor also gives a mark of 0-5 for Global Achievement. Marks for all criteria are then combined, hence, there are 30 points available in the Speaking test. There are two examiners in the room. One examiner talks to the participants and the other examiner listens to them. Both examiners give them marks. The test lasts approximately for 10-12 minutes.

Achievement Test - In order to test the participants' achievement in respect to speaking fluency and accuracy based on activities in the class, an achievement test was administered to both experimental and control groups. The test was added to the end of the speaking section of PET and served as the post-test of this study. This achievement test was based on the three sets of vocabulary which was taught through collocations in the experimental group and on a single word basis in the control group and the three related topics which were discussed in the two groups. Each participant was asked some questions about one of the topics and was given a few minutes to answer the questions and express his/her opinion about it. Then, the participant's speaking fluency and accuracy were rated by two raters and a score of 0-5 was given for each criterion. The reliability of the results in the placement test, pre-test and post-test were estimated through inter-rater reliability measures, i.e., Pearson correlation coefficients between the ratings of the two raters in the tests were calculated. These correlations (all at 0.01 alpha level) were as follows: Placement Test, .719; Pretest Fluency, 780; Pretest Accuracy, .892; PET Fluency Posttest, .860; PET Accuracy Posttest, .831; Achievement Fluency Posttest, .943; Achievement Accuracy Posttest, .982.

\subsection{Procedures}

The general oral proficiency of 50 pre-intermediate female EFL students was rated according to the speaking section of a PET. Thirty participants who scored midway on the score range were selected for the study. They were randomly divided into two groups of fifteen, one as experimental and the other as control group. T-tests ensured their homogeneity of oral proficiency as well as speaking fluency and accuracy (see below).

Having administered the pre-test, three interesting topic-based section of vocabulary were chosen from Intermediate Vocabulary authored by B.J. Thomas (1986). In the experimental group new vocabulary was instructed in the context of collocations. First, the teacher listed ten new items from each topic on the board. The students looked for the new words, their collocations and an example for each, if any, in Longman Active Study Dictionary. They wrote the words, their collocations and examples in their notebooks as their homework assignment. In the following session they checked their findings with a partner as pair work and then presented them to the class. The teacher chose the most practical and memorable example and wrote it on the board. The example for each word included the collocation of that word and was emphasized by the teacher. The students added that example to their notes. Everybody was supposed to study the selected examples for the next session.

As stated before, the new words were topic-based, so students were also asked to think about that topic in the following session. They were also encouraged to use the target vocabulary and their collocations while expressing their opinion about the selected topic. Three topics and three sets of vocabulary were covered during three weeks. The same topics and vocabulary were targeted for the control group during this time span. New words were listed on the board, yet students were not assigned to check them in any dictionaries. Instead, the teacher defined and taught them on a single word basis. No collocations were taught for the new words. The participants in the control group were asked to prepare for the following session and then encouraged to use the target words in their speaking. After the treatment, the PET speaking fluency and accuracy post-tests and other related measures were administered as described above.

\subsection{Data analysis}

The data collected for this study were analyzed quantitatively with the help of Statistical Package for Social 
Memarian-Mojarab, M., \& Farjami, H.

Sciences (SPSS) Version19. Descriptive statistics were calculated for all variables. Numerical values were summarized as means, \pm SDs, and variances and inferential statistics were calculated. An independent t-test was run to ensure about homogeneity of the sample regarding the general oral proficiency. Moreover, based on the results of the pre-test, an independent $t$-test was administered to ensure the two groups were homogeneous with respect to speaking fluency and accuracy. An independent t-test was administered based on the results of the post-test to see if there was any difference in performance of the two groups with respect to speaking fluency and accuracy.

\section{Results}

\subsection{Homogeneity test for fluency and accuracy}

According to Table 1, the mean scores of experimental and control groups for fluency on the pre-test were $3.91(S D=.53)$ and $3.71(S D=.50)$, respectively. In addition, their pre-test means for accuracy were $3.60(S D=.50)$ and $3.58(S D=.32)$ in the same order.

\section{Table 1}

Descriptive statistics for fluency and accuracy of participants at pre-tests

\begin{tabular}{llccc}
\hline & Groups & $n$ & Mean & $S D$ \\
\hline Fluency pretest & Control & 15 & 3.71 & .50 \\
& Experimental & 15 & 3.91 & .53 \\
\hline \multirow{2}{*}{ Accuracy pretest } & Control & 15 & 3.58 & .32 \\
& Experimental & 15 & 3.60 & .50 \\
\hline
\end{tabular}

Independent-sample t-tests were used to compare the mean scores for fluency and accuracy in the pre-test. The results showed that there was not any significant difference between the groups in fluency $(t(28)=.1 .05$, $p=.302)$ and accuracy $(t(28)=.10, p=.915)$ at the pre-test stage. Levene's test pointed to the groups' homogeneity of variance on the fluency $(F=.051, p=.82)$ and accuracy $(F=2.93, p=.098)$.

\subsection{Teaching collocations and improvement of fluency}

Table 2 shows the descriptive statistics for the scores of the two groups for fluency post-test. The mean score of the experimental group in fluency post-test was 4.45 ( $S D=.47)$, and the mean score of the control group in fluency post-test was $4.05(S D=52)$.

\section{Table 2}

The descriptive statistics of groups in the fluency post-test

\begin{tabular}{llccc}
\hline & Groups & $n$ & Mean & SD \\
\hline Fluency posttest & Control & 15 & 4.05 & .52 \\
& Experimental & 15 & 4.45 & .47 \\
\hline
\end{tabular}

To find that this difference was significant, a t-test was run. There was a significant difference between the scores of the two groups in fluency post-test $(t(28)=2.13, p=.042)$. To ensure the reliability of the results of fluency post-test of PET, the researcher also used an achievement test as the second post-test of this study. Table 3 shows the descriptive statistics of groups in the second fluency post-test. As this table shows, the mean score of experimental group in the second fluency post-test was 4.48(SD=.51), and the mean score of control group in the second fluency post-test was 3.35(SD=.47). 
Comparing the effect of teaching collocations versus single words on speaking fluency and accuracy

Table 3

The descriptive statistics of groups in the second fluency post-test

\begin{tabular}{llccc}
\hline & Groups & $n$ & Mean & $S D$ \\
\hline Second fluency posttest & Control & 15 & 3.35 & .47 \\
& Experimental & 15 & 4.48 & .51 \\
\hline
\end{tabular}

To find that this difference was significant, a t-test was run. There was a significant difference between the scores of the two groups in the second fluency post-test $(t(28)=6.29, p=.000)$. Therefore, it can be claimed that collocation-based teaching of vocabulary improved students' speaking fluency more than teaching vocabulary based on single words.

\subsection{Teaching collocations and improvement of accuracy}

The second research question was "Does collocation-based teaching of vocabulary to Iranian EFL learners improve their speaking accuracy more than single word-based teaching of vocabulary?" Table 4 shows the descriptive statistics for the scores of the two groups in accuracy post-test. According to this table, the mean score of experimental group in accuracy post-test was $4.15(S D=.47)$, and the mean score of control group in accuracy post-test was $3.77(S D=.39)$.

\section{Table 4}

The Descriptive Statistics of groups in the accuracy post-test

\begin{tabular}{llccc}
\hline & Groups & $n$ & Mean & $S D$ \\
\hline Accuracy posttest & Control & 15 & 3.77 & .39 \\
& Experimental & 15 & 4.15 & .47 \\
\hline
\end{tabular}

To see whether the difference between the mean scores of the accuracy post-tests of the two groups was significant, a t-test was run. There was a significant difference between the scores of the two groups in accuracy at the post-test phase $(t(28)=2.34, p=.026)$. To ensure the reliability of the results of the post-test of PET, an achievement test was used as the second post-test to investigate participants' speaking accuracy. Table 5 shows the descriptive statistics for the scores of the two groups in the second accuracy post-test. According to this table, the mean score of the experimental group in the second accuracy post-test was $4.34(S D=.53)$, and the mean score of the control group in the second accuracy post-test was $2.27(S D=.56)$.

\section{Table 5}

The Descriptive statistics of groups in the second accuracy post-test

\begin{tabular}{llccc}
\hline & Groups & $n$ & Mean & SD \\
\hline Second accuracy posttest & Control & 15 & 2.27 & .56 \\
& Experimental & 15 & 4.34 & .53 \\
\hline
\end{tabular}

To check the significance of the difference between the means, a t-test was run. There was a significant difference between the scores of the two groups in the second accuracy post-test $(t(28)=8.01, p=.000)$. Therefore, it can be claimed that collocation-based teaching of vocabulary improves students' speaking accuracy more than teaching vocabulary based on single words.

\section{Discussion and conclusion}

The results of the post-tests revealed that the experimental group's speaking fluency considerably improved in comparison with the pre-test's score. This group also outperformed the control group in speaking accuracy while they were homogeneous in the beginning.

One reason for the students' better performance regarding speaking fluency in experimental group could be that they learned each word along with their collocations; consequently, when they intended to use 
newly-learned words in their speaking, they immediately remembered their collocations, and did not spend time thinking about how to create their sentences and convey their messages. In other words, they seemed to be speaking more effortlessly than students in the control group and sounded more fluent and native like. Related to this, Ghezelseflou and Seyedrezaei (2015) found that vocabulary instruction via collocations resulted in better retention of the words than teaching them by means of traditional techniques; this means that vocabulary instruction by means of collocations can be a successful strategy in assisting students to remember and make use of the new vocabulary without difficulty in EFL classrooms.

Strong associations among words and better retention and easier access of vocabulary learned through collocations can be only one reason for fluency. A stronger reason can be the psychological reality of collocations and formulaic sequences, in the sense that they are directly stored in and accessed from the mental lexicon (Aitchison, 2003; Fitzpatrick, 2006). Arguably, this is why, according to Pawley and Syder (1983), chunked expressions enable learners to reduce cognitive effort, save processing time, and have language available for immediate use. Obviously, direct access also leads to lighter cognitive load and enhances the speed with which language is processed and the fluency and automaticity with which it is produced.

Surprisingly, the students in the experimental group also performed better than the students in the control group with respect to speaking accuracy although there was no explicit teaching of grammar or any implicit grammar agenda. It can be argued that these students were exposed to more context than the others. They checked their dictionaries for the target words and found illustrative examples for them. This exposure to authentic examples and attempt at memorizing whole chunks can be a possible reason for their significant improvement in speaking accuracy. Psycholinguistically speaking, improved accuracy in the experimental group could be a result of better vocabulary and lexical access and the availability of free working memory and cognitive bandwidth to enable the language users to take care of issues beyond bare necessities in the execution of communicative tasks (for detailed accounts of channel capacity, working memory, and executive control (see Baddeley, Chinocotta, \& Adlam, 2001; Logan, 2004).

The insignificant change in the control group for fluency and accuracy can be attributed to the fact that vocabulary was taught out of context in this group. Presumably, students in this group resorted to a word-by-word translation of the intended ideas in their mother tongue into English. Supporting this assumption, Koosha and Jafarpoor (2006) concluded, after analysis of errors of collocations that Iranian EFL learners carried over their L1 collocational patterns to their L2 production. They claimed that, although phonological transfer is most common in second language acquisition, lexical and collocational transfer seems to be a common cause of poor proficiency. More directly, O'keefe, MacCarthy, and Carter (2007) commented that "an overemphasis in language teaching on single words out of context might leave second language learners ill-prepared both in terms of the processing of heavily chunked input, such as casual conversation, as well as in terms of their own productive fluency." (p. 63)

The results of this study manifested that English learners with better knowledge of collocations speak more fluently and accurately. Therefore, it can be concluded that collocation instruction positively affects productive skills. An important issue is the source of collocations. In this study, they were found in a dictionary which normally includes authentic and illustrative examples. While dictionary examples may not be the best contexts, this study suggests that collocation instruction should be contextual and collocations should be selected from appropriate sources. The results of the current research have messages for course and syllabus designers and material developers, particularly those who work in the area of speaking. Language teaching practitioners need to remember that students should not just learn single vocabulary items in order to be fluent and accurate English speakers. Collocation instruction deserves a high place in vocabulary instruction and grammar instruction may be effectively supported by this important part of lexis.

The claims of this study could be stronger if there were a larger number of participants and more collocation tasks. The measurement tasks were also limited by practical considerations. Future researchers can investigate 
the communicative efficiency of teaching collocations with more advanced learners. For surer conclusions, future researchers are advised to use delayed posttests, too. It is also suggested that future studies take learning styles into consideration when investigating the relative effects of teaching collocations on different aspects of communication.

\section{References}

Aitchison, J. (2003). Words in the mind ( $3^{\text {rd }}$ ed.). Oxford: Blackwell.

Alderson, J. C. (2005). Diagnosing foreign language proficiency: The interface between learning and assessment. London: Continuum.

Arnaud, P. J. L., \& Savignon, S. S. (1997). Rare words, complex lexical units and the advanced learner. In J. Coady \& T. Huckin (Eds.), Second language vocabulary acquisition: A rationale for pedagogy (pp. 157-173). Cambridge: Cambridge University Press. https://doi.org/10.1017/CBO9781139524643.012

Baddeley, A. D., Chincotta, D., \& Adlam, A. (2001). Working memory and the control of action: Evidence from task switching. Journal of Experimental Psychology: General, 130, 641-657. https://doi.org/10.1037/0096-3445.130.4.641

Biber, D., \& Conrad, S., Reppen, R. (1998). Corpus linguistics: Investigating language structure and use. Cambridge: Cambridge University Press.

Biber, D., Johansson, S., Leech, G., Conrad, S., \& Finegan, E. (2002). Longman grammar of spoken and written English. Harlow: Pearson Education. https://doi.org/10.1017/CBO9780511804489

Boers, F., Eyckmans, J., Kappel, J., Stengers, S. \& Demecheleer, M. (2006). Formulaic sequences and perceived oral proficiency: Putting the lexical approach to the test. Language Teaching Research, 10, 245-261. https://doi.org/10.1191/13621688061r195oa

Brazil, D. (1995). A grammar of speech. Oxford: Oxford University Press.

Croft, W., \& A. Cruise. (2004). Cognitive linguistics. Cambridge: Cambridge University Press. https://doi.org/10.1017/CBO9780511803864

Ellis, N. C. (2001). Memory for language. In P. Robinson (Ed.), Cognition and second Language Instruction (pp. 33-68). Cambridge: Cambridge University Press. https://doi.org/10.1017/CBO9781139524780.004

Ellis, N. C. (2006). Language acquisition as rational contingency learning. Applied Linguistics, 27(1), 1-24. https://doi.org/10.1093/applin/ami038

Fitzpatrick, T. (2006). Habits and rabbits: Word associations and the L2 lexicon. EUROSLA Yearbook, 6, 121-145. https://doi.org/10.1075/eurosla.6.09fit

Ghezelseflou, M., \& Seyedrezaei, S. H. (2015). The effect of teaching vocabulary through collocations on the vocabulary retention of Iranian EFL students. International Journal of Basic Sciences \& Applied Research, 4(3), 162-170.

Goldberg, A. E. (2006). Constructions at work: The nature of generalization in language. Oxford: Oxford University Press.

Halliday, M. A. K. (1966). Lexis as linguistic level. Journal of Linguistics, 2(1), 57-67. https://doi.org/10.1017/S0022226700001328

Harmer, J. (2001). The practice of English language teaching. New York: Longman. https://doi.org/10.1177/003368820103200109

Howarth, P. (1998). The phraseology of learners' academic writing. In A. P. Cowie (Ed.), Phraseology: Theory, analysis, and applications (pp. 161-186). Oxford: Oxford University Press.

Hunston, S., \& Francis, G. (1996). Pattern grammar: A corpus driven approach to the lexical grammar of English. Amsterdam: John Benjamins.

Jong, N. H., Steinel, M. P., Florijn, A. F., Schoonen, R., \& Hulstijn, J. H. (2012). Facets of speaking proficiency. Studies in Second Language Acquisition, 34(1), 5-34. https://doi.org/10.1017/S0272263111000489

Koosha, M., \& Jafarpour, A. A. (2006). Data-driven learning and teaching collocation of prepositions: The case of Iranian EFL adult learners. Asian EFL Journal, 8(4), 192-202.

Koya, T. (2006). What is the reality of collocation use by native speakers of English? Dialogue, 5, 1-18. 
Memarian-Mojarab, M., \& Farjami, H.

Leech, L. (2000). Grammars of spoken English: New outcomes of Corpus-oriented research. Language Learning, 50, 675-724. https://doi.org/10.1111/0023-8333.00143

Lewis, M. (1993). The lexical approach: The state of ELT and the way forward. Hove, England: Language Teaching Publications.

Lewis, M. (1997). Implementing the lexical approach. London: Language Teaching Publication.

Logan, G. D. (2004). Working memory, task switching, and executive control in the task span procedure. Journal of Experimental Psychology, 133, 218-236. https://doi.org/10.1037/0096-3445.133.2.218

Longman Active Study Dictionary. (2010). London: Pearson Longman.

McCarthy, M. J. (2004). Collocation in vocabulary teaching and learning. Lecture given at the meeting of JACET summer seminar program, Gunma, Japan.

McEnery, T., \& Wilson. A. (1996). Corpus linguistics. Edinburgh: Edinburgh University Press.

Nation, I. S. P. (2008). Teaching vocabulary: Strategies and techniques. Boston: Heinle.

Nation, I. S. P. (2014). What you need to know to learn a foreign language. Wellington: Victoria University of Wellington.

Nesselhauf, N. (2003). The use of collocations by advanced learners of English and some implications for teaching. Applied Linguistics, 24(2), 223-242. https://doi.org/10.1093/applin/24.2.223

O’keefe, A., M. MacCarthy, \& R. Carter. (2007). From corpus to classroom. Cambridge: Cambridge University Press. https://doi.org/10.1017/CBO9780511497650

Pawley, A., \& Syder, F. H. (1983). Two puzzles for linguistic theory: Native-like selection and native-like fluency. In J. C. Richards \& R. W. Schmidt (Eds.), Language and communication (pp. 191-226). London: Longman.

Révész, A., Ekiert, M., \& Torgersen, E. N. (2016). The effects of complexity, accuracy, and fluency on communicative adequacy in oral task performance. Applied Linguistics, 37(6), 828-848. https://doi.org/10.1093/applin/amu069

Schmitt, N. (2010). Researching vocabulary: A vocabulary research manual. Basingstoke: Palgrave Macmillan. https://doi.org/10.1057/9780230293977

Sinclair, J. (1991). Corpus, concordance and collocation. Oxford: Oxford University Press.

Skehan, S. (2009). Modelling second language performance: Integrating complexity, accuracy, fluency, and lexis. Applied Linguistics, 30(4), 510-532. https://doi.org/10.1093/applin/amp047

Thomas, B J. (1986). Intermediate vocabulary. Hong Kong: Longman.

Webb, S., Newton, J., \& Chang, A. (2013). Incidental learning of collocation. Language Learning, 63(1), 91-120. https://doi.org/10.1111/j.1467-9922.2012.00729.x

Wouden, T. V. (1997). Negative contexts: Collection, polarity, and multiple negation. New York: Routledge.

Wray, A. (2002). Formulaic language and the lexicon. Cambridge: Cambridge University Press. https://doi.org/10.1017/CBO9780511519772

Zhang, X. (1993). English collocations and their effect on the writing of native and non-native college freshmen [Doctoral dissertation]. Indiana University of Pennsylvania, Indiana, USA. 